\title{
The Sheffield chair for cardiopulmonary resuscitation
}

\author{
D. L. EDBROOKE, J. WARDROPE, A. C. CROSBY, R. MURRAY \\ \& D. G. FERGUSON \\ Department of Accident and Emergency Medicine, Royal Hallamshire Hospital, Sheffield, \\ England
}

\section{INTRODUCTION}

The general public is becoming more aware of cardiac arrest, and the importance of early resuscitation and call out of the emergency services. At present in the United Kingdom, most out of hospital cardiac arrests are transported to hospital by ambulance with single-operator cardiopulmonary resuscitation (CPR) performed by ambulance personnel during transport. Despite the introduction of extended training for ambulance personnel, it is unlikely that more than one operator will be available to perform CPR during the journey time. Personal experience of attempting practical procedures in moving ambulances prompted the authors to examine cardiopulmonary resuscitation in this situation in an attempt to make patient care more satisfactory.

\section{METHOD}

Five people with extensive experience of cardiopulmonary resuscitation (three doctors and two ambulancemen with extended training skills) took part in the trial. Singleoperator cardiopulmonary resuscitation was performed on a recording manikin (Laerdal).

A period of CPR was performed stationary in the ambulance to ensure that the technique was satisfactory. Cardiopulmonary resuscitation was then performed for two periods of $4 \mathrm{~min}$ in an ambulance travelling around a standard route. During the first spell, the operator performed the CPR either kneeling, using two hands for the CPR, or standing, with one hand for support and one hand for the CPR, according to personal preference.

During the second period, a modified seat was used to provide a more stable platform

Correspondence: Dr D. L. Edbrooke, Department of Accident and Emergency Medicine, Royal Hallamshire Hospital, Glossop Road, Sheffield S10 $2 \mathcal{F F}$, England 
for the operator. This seat is the standard single seat located at the front part of the patient compartment of most ambulances. This is designed to be removable and clip om the side of the patient trolley. The authors have modified this with an attachment to the seat which makes the seat tilt at an angle of $45^{\circ}$ towards the patient, giving a much mote stable position for performing CPR (Figs $1 \& 2$ ).

For each of these periods, the recorded traces were analyzed for the depth of che compression and the volume of respiration achieved. The height of the first 10 compressions for each trace were measured and the amount of respiration for the first 20 breaths. This data was then recorded onto the Unistat Statistics package and analyzed using Student's $t$-test.

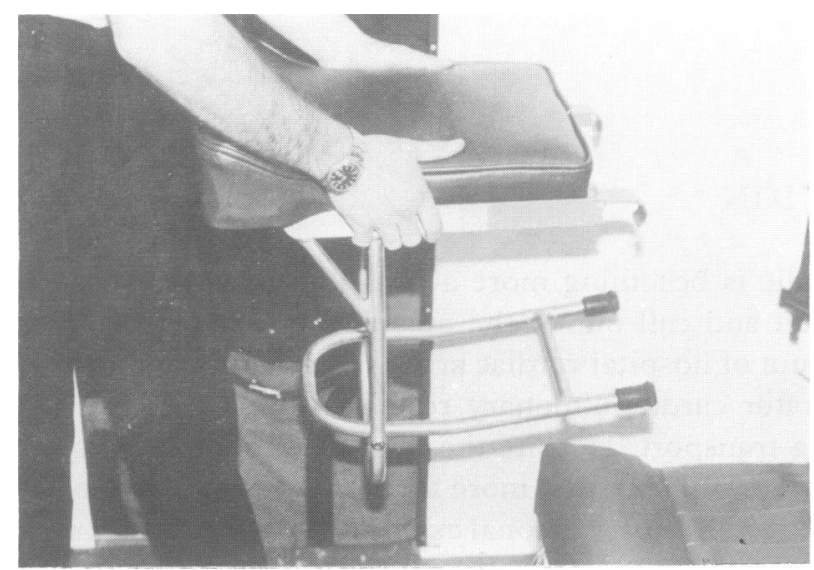

Fig. 1 The Sheffield chair for cardiopulmonary resuscitation.

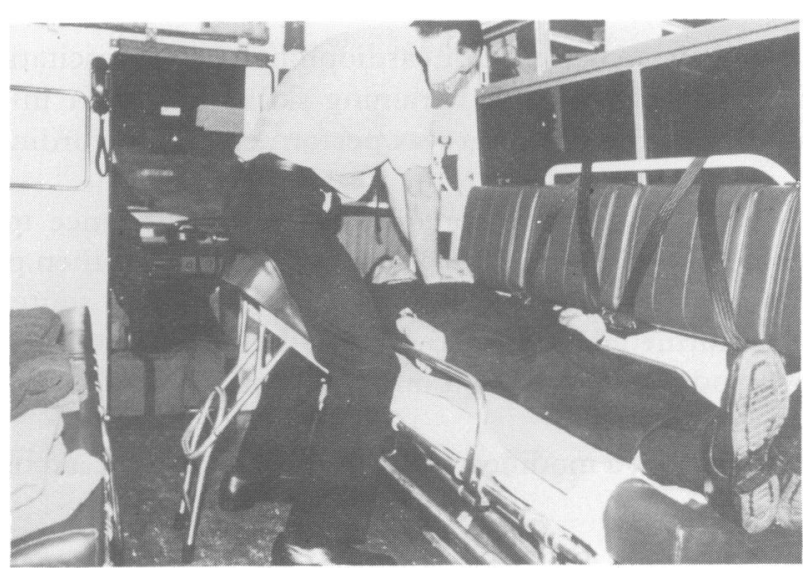

Fig. 2 The chair clipped to the side of the patient trolley and tilted at an angle of $45^{\circ}$ to the patient. 


\section{RESULTS}

All the participants in the trial found the seat much safer as there was not the same tendency to be thrown around the vehicle during acceleration, braking and cornering. The position the seat gave made the performance of the CPR easier. The figures from the recording manikin confirm that the external cardiac compression was more effective using the seat in all operators and this difference was highly significant in four out of five (Table 1). The amount of lung inflation was similarly increased significantly in three operators. All the operators felt that the CPR was a great deal easier to do as it was possible to achieve a much more stable position.

Table 1 Depth of chest compression and volume of respiration achieved

\begin{tabular}{|c|c|c|c|c|c|c|}
\hline \multirow[t]{2}{*}{ Operator } & \multicolumn{2}{|c|}{$\begin{array}{l}\text { Compression: } \\
\text { mean compression }(\mathrm{mm}) \\
(\mathrm{St} \mathrm{Dev})\end{array}$} & \multirow[t]{2}{*}{$P$} & \multicolumn{2}{|c|}{$\begin{array}{l}\text { Respiration: } \\
\text { mean breath (1) } \\
(\text { St Dev })\end{array}$} & \multirow[t]{2}{*}{$P$} \\
\hline & No seat & Seat & & No seat & Seat & \\
\hline 1 & $\begin{array}{l}23.9 \\
(3.5)\end{array}$ & $\begin{array}{l}24 \cdot 8 \\
(3 \cdot 2)\end{array}$ & $>0.05$ & $\begin{array}{c}0.73 \\
(0.14)\end{array}$ & $\begin{array}{c}0.89 \\
(0.12)\end{array}$ & $<0.005$ \\
\hline 2 & $\begin{array}{l}22 \cdot 7 \\
(6 \cdot 7)\end{array}$ & $\begin{array}{l}29 \cdot 2 \\
(3 \cdot 1)\end{array}$ & $<0.001$ & $\begin{array}{c}0.83 \\
(0.25)\end{array}$ & $\begin{array}{l}0.99 \\
(0.3)\end{array}$ & $>0.05$ \\
\hline 3 & $\begin{array}{l}27 \cdot 1 \\
(5 \cdot 1)\end{array}$ & $\begin{array}{l}33.5 \\
(2 \cdot 4)\end{array}$ & $<0.001$ & $\begin{array}{c}1.26 \\
(0 \cdot 16)\end{array}$ & $\begin{array}{c}1 \cdot 46 \\
(0 \cdot 15)\end{array}$ & $<0.001$ \\
\hline 4 & $\begin{array}{l}24 \cdot 2 \\
(4 \cdot 2)\end{array}$ & $\begin{array}{l}27 \cdot 2 \\
(3 \cdot 2)\end{array}$ & $<0.001$ & $\begin{array}{c}0.84 \\
(0.20)\end{array}$ & $\begin{array}{c}1.09 \\
(0.11)\end{array}$ & $<0.001$ \\
\hline 5 & $\begin{array}{l}22 \cdot 9 \\
(5 \cdot 5)\end{array}$ & $\begin{array}{l}30 \cdot 4 \\
(2 \cdot 7)\end{array}$ & $<0.001$ & $\begin{array}{c}1.45 \\
(0.24)\end{array}$ & $\begin{array}{c}1.45 \\
(0.20)\end{array}$ & $>0.5$ \\
\hline
\end{tabular}

\section{DISCUSSION}

Since the original description of closed chest cardiac compression and mouth-to-mouth resuscitation (Jude et al., 1961) many studies have repeatedly demonstrated its efficacy. Despite this, little work has been reported on the effects on CPR efficiency in the moving ambulance (Benson et al., 1972). In the last 12 months, 90 out-of-hospital cardiac arrests arrived at the Royal Hallamshire Hospital, Sheffield, England, alone, with an average transit time of approximately $10 \mathrm{~min}$. This indicates that $15 \mathrm{~h}$ of CPR during transit were necessary in one year. As a result, it is important that CPR is conducted in the safest and most efficient way.

Many studies have shown that the pneumatic chest compression device (thumper) is effective and has the advantage that it performs efficiently in a relatively unstable environment (Kern et al., 1985). However, these machines are expensive and it is unlikely in the present financial climate that these can be installed in all ambulances. The use of this small simple modification also makes general patient care much easier during transport. The cost of the modification is minimal as the moveable seat is part of the standard ambulance furniture. 
The seat is now on extended trial with the South Yorkshire Metropolitan Ambulan Service and initial reports suggest that it will be accepted as part of the standar ambulance equipment in this area.

\section{ACKNOWLEDGEMENT}

We wish to acknowledge the help of the South Yorkshire Metropolitan Service for the cooperation in making this study possible. In addition, we have been asked to point oụ that the model illustrated is a prototype and not the production model.

\section{REFERENCES}

Bensen D. M., Esposito G. \& Dirsch J. (1972) Mobile intensive care by 'unemployable' blacks trained \& emergency medical technicians in 1967-69. Fournal of Trauma 12, 408-21.

Jude J. R., Kouwenhoven W. B. \& Knickerbocker C. G. (1961) Cardiac arrest, a report of application $\delta$ f external cardiac massage on 118 patients. Fournal of the American Medical Association 178, 1063-70.

Kern C. B., Carter A. B. \& Showen R. L. (1985) Manual versus mechanical cardiopulmonary resuscitation i⿱ an experimental canine mode. Critical Care Medicine 13, 899-903. 